
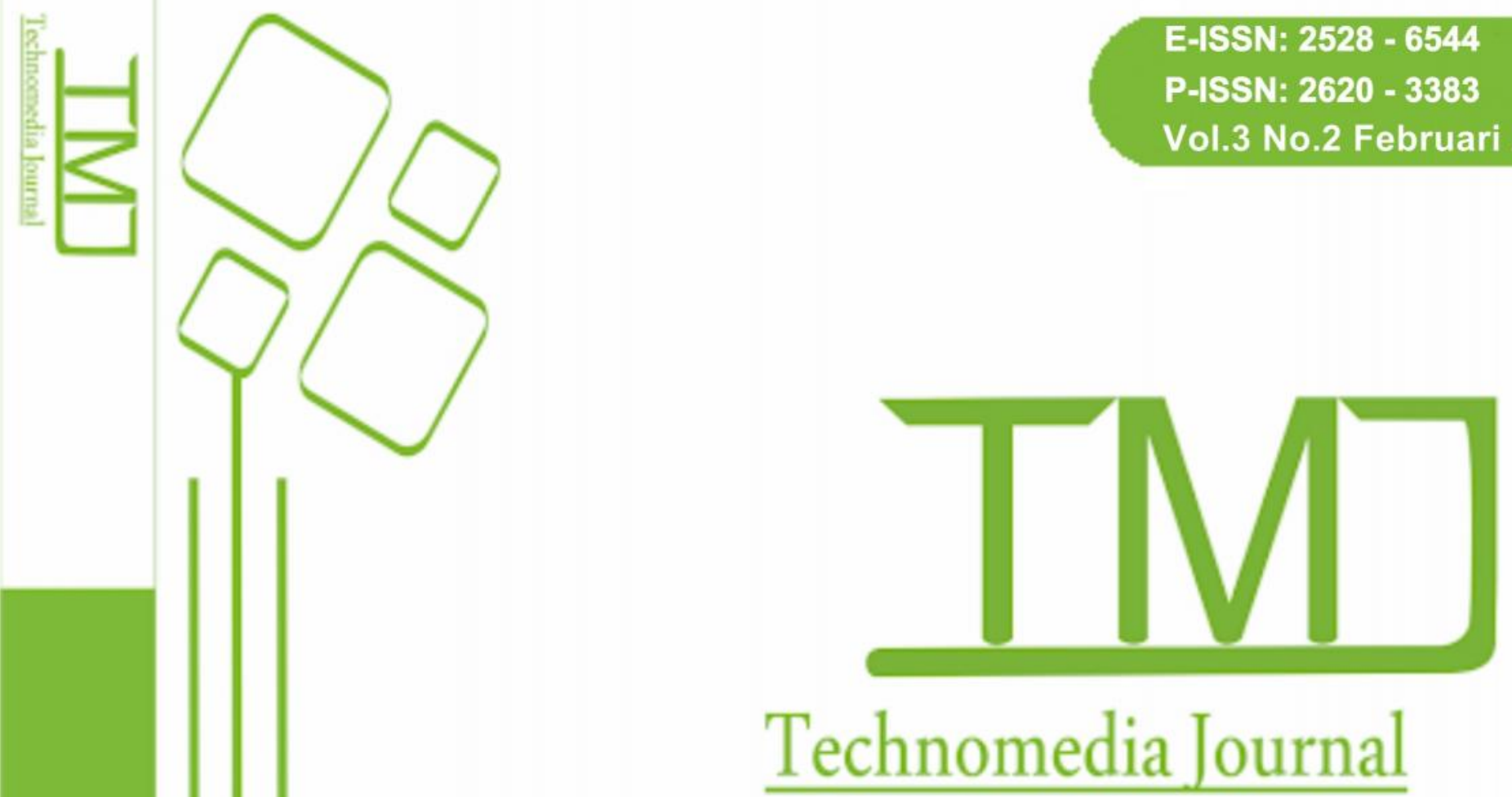

Technomedia Journal

iLearning Journal Center (iJC)

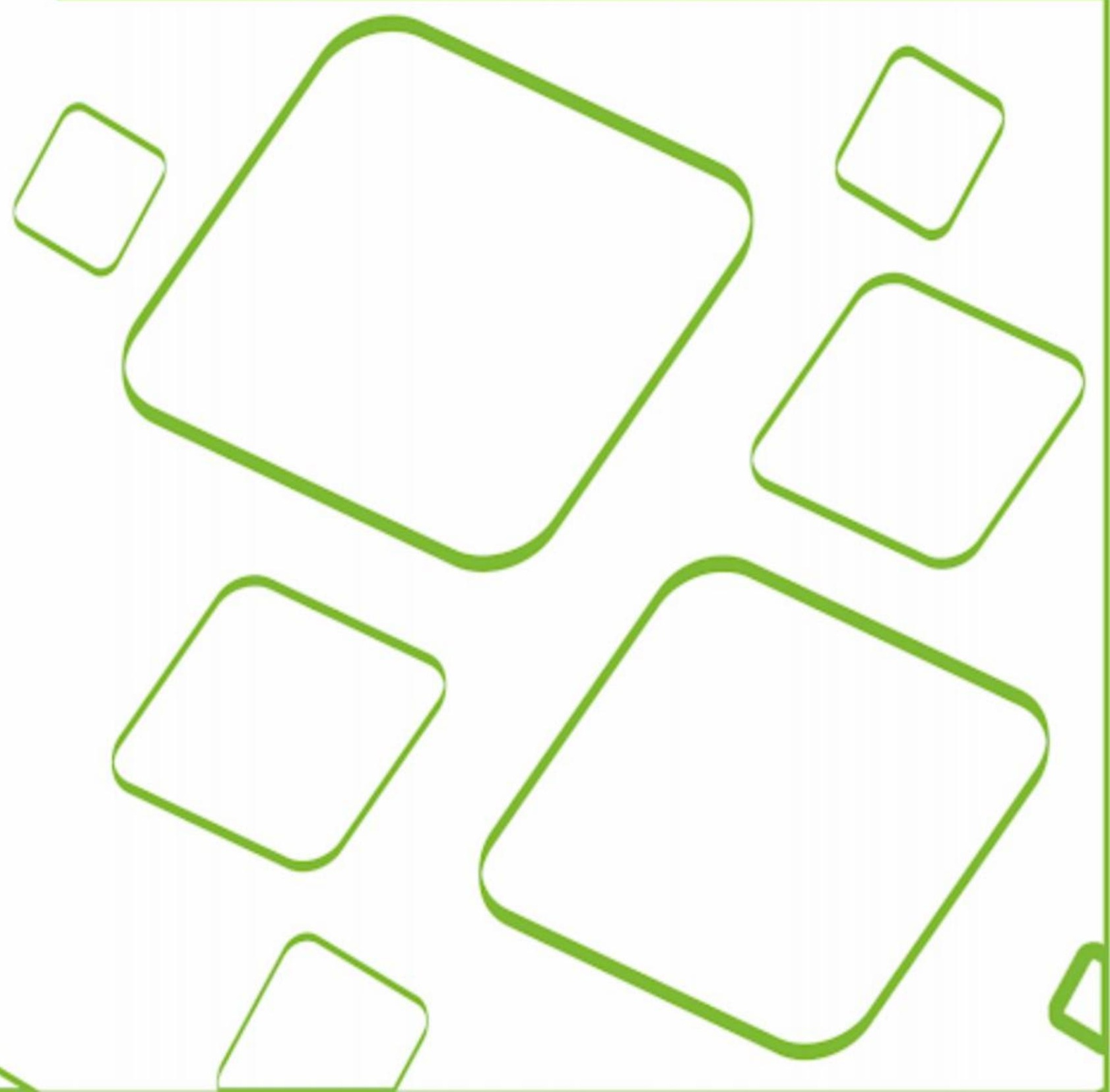




\title{
Pengaruh Fingerprint Terhadap Jam Kerja Lembur di Perusahaan PT. Jasapower Indonesia
}

\author{
Mustafa Bakeri ${ }^{1}$ \\ Juhriyansyah Dalle ${ }^{2}$ \\ Graduate Program of Business Administration ${ }^{1}$ \\ Department of Information Technology ${ }^{2}$ \\ Universitas Lambung Mangkurat, Banjarmasin, Indonesia \\ e-mail:mustafa.bakeri@ptjpi.com ${ }^{1)}$,j.dalle@ulm.ac.id ${ }^{2}$
}

\begin{abstract}
ABSTRAK
Jam kerja lembur sangat mempengaruhi terhadap pendapatan atau benefit karyawan, khususnya karyawan non staf. Untuk itu diperlukan sistem elektronik yang dapat menginput data kehadiran karyawan. Penginputan data tersebut menggunakan sistem absensi fingerprint yang telah terhubung ke database karyawan. Tujuan dari penelitian ini yaitu untuk mengetahui penerapan sistem absensi fingerprint dan perhitungan jam kerja lembur karyawan di perusahaan PT. Jasapower Indonesia. Sample yang digunakan pada penelitian ini yaitu karyawan staf dan karyawan non staf, serta bagaimana berjalannya proses absensi. Hasil dari penelitian menyatakan bahwa kehadiran karyawan setelah melakukan absensi fingerprint akan sangat mempengaruhi jumlah jam kerja lembur karyawan. Maka dengan ini disimpulkan sistem absensi fingerprint sangat efektif digunakan untuk perhitungan jam kerja lembur karyawan non staf dan juga dapat mendorong karyawan menjadi lebih disiplin, serta memotivasi karyawan untuk selalu menjaga kondisi badan fit dan dapat berhadir untuk bekerja.
\end{abstract}

Kata kunci: kehadiran, sidik jari, jam kerja lembur

\section{ABSTRACT}

Overtime hours affect employees' income or benefits, especially non-staff employees. For that we need an electronic system that can input employee attendance data. Inputting the data uses a fingerprint attendance system that has been connected to the employee database. The purpose of this study is to find out the application of the fingerprint attendance system and the calculation of employee overtime hours in the company PT. Jasapower Indonesia. The sample used in this study is staff staff and non-staff employees, and how the attendance process works. The results of the study state that the presence of employees after doing a fingerprint attendance will greatly affect the number of hours of overtime employees. So with 171| Mustafa, Juhriyansyah - Pengaruh Fingerprint Terhadap Jam Kerja Lembur di ..... 
this it is concluded that the fingerprint attendance system is very effective used for calculating overtime hours of non-staff employees and can also encourage employees to be more disciplined, and motivate employees to always maintain a fit and able body condition to work.

Keywords: attendance, fingerprint, overtime hours

\section{PENDAHULUAN}

Perkembangan ilmu pengetahuan di segala bidang dalam era globalisasi saat ini begitu pesat. Terutama dalam bidang IT yang semakin maju seiring dengan kebutuhan pemakai (user). Canggihnya dunia teknologi dewasa ini mengharuskan kita untuk mengikuti perkembanganya jika tidak maka kita akan semakin jauh tertinggal oleh negara lain khususnya dalam bidang perusahaan.Penggunaan sidik jari untuk absensi karyawan bisa menjadi solusi cara absensi yang lebih baik karna dengan sidik jari karyawan harus hadir sendiri untuk kehadirannya, Sidik jari telah terbukti cukup aman dan nyaman bila di bandingkan dengan sistem pengenalan identitas manusia lainnya seperti bentuk wajah, warna, suara dan retina mata. Sidik jari manusia sedemikian uniknya sehingga tidak ada seorangpun yang memiliki sidik jari yang identik dengan orang lain, meskipun antara saudara kembar. Oeh karena itu perlu adanya sistem absensi sidik jari yang diharapkan dapat meningkatkan kinerja di Perusahaan PT. Jasapower Indonesia.

\section{PERMASALAHAN}

Perusahaan PT. Jasapower Indonesia, yaitu perusahaan yang bergerak dibidang jasa Pertambangan yang memiliki karyawan yang cukup banyak sehingga data - data absensi karyawan tersebut harus terorganisir dengan baik. Karena, data absensi kehadiran tersebut diharapkan dapat digunakan untuk perhitungan jam kerja lembur yang sangat berpengaruh pada benefit karyawan.

\section{TINJAUAN PUSTAKA}

\section{Pengertian Sidik Jari}

Sidik Jari merupakan identitas pribadi yang tidak mungkin ada yang menyamainya. Sifat-sifat atau karakteristik yang dimiliki oleh sidik jari adalah parennial nature yaitu guratan-guratan pada sidik jari yang melekat pada manusia seumur hidup, immutability yang berarti bahwa sidik jari seseorang tak akan pernah berubah kecuali sebuah kondisi yaitu terjadi kecelakaan yang serius sehingga mengubah pola sidik jari yang ada dan individuality 
yang berarti keunikan sidik jari merupakan originalitas pemiliknya yang tak mungkin sama dengan siapapun di muka bumi ini sekali pun pada seorang yang kembar identik.

\section{Sensor Sidik Jari}

Dibawah ini merupakan struktur umum dari scanner sidik jari dimana sebuah sensor membaca permukaan jari dan merubah pembacaan analog ke dalam digital melalui sebuah A/D konverter (Analog ke Digital), sebuah modul interface bertanggung jawab untuk berkomunikasi (mengirim gambar, menerima perintah, dan sebagainya) dengan alat luar (personal computer / PC). Jari menyentuh sisi atas dari kaca prisma, tapi ridges mulai bersentuhan dengan permukaan prisma, bekas valley pada jarak pasti. Pada sisi kiri prisma menerangi melalui suatu cahaya yang menyebar. Cahaya masuk ke prisma dicerminkan pada valley, dan secara acak menyebar (menyerap) pada ridges. Pantulan yang kurang memberikan ridges menjadi berbeda-beda dari valleys. Sinar cahaya keluar dari sisi kanan prisma dan fokus melaui lensa diatas CCD atau CMOS sensor gambar. Karena alat FTIR berguna untuk permukaan 3 dimensi, ini tidak dapat dengan mudah menipu pemberian foto atau cetak gambar dari sidik jari. Ketika jari sangat kering, itu tidak dapat membuat kontak yang sama dengan permukaan sensor. Memperbaiki pembentukan sidik jari dari jari yang kering yang mana ridge tidak mengandung partikel keringat, beberapa penghasil scanner menggunakan lapisan silikon yang menyerupai kontak dari permukaan dengan prisma. Dengan tujuan mengurangi biaya dari alat optik, plastik pada saat sekarang sering kali digunakan dibandingkan kaca prisma, dan lensa.

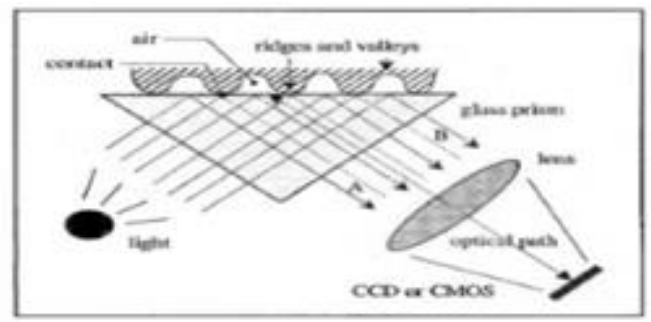

\section{Gambar 1 Sensor Sidik Jari Dengan FTIR}

(Sumber : Sinaga, Triandes \& Tamba, Takdir, 2013)

Dimana seperti pada percobaan Newton menjelaskan bahwa cahaya putih (polikromatis) bila dilewatkan terhadap prisma akan mengalami gejala disperse yaitu gejala peruraian cahaya putih menjadi cahaya monokromatik (merah, jingga, kuning, hijau, biru, nila, dan ungu), cahaya-cahaya ini memiliki panjang gelombang yang berbeda. Setiap panjang gelombang memiliki indeks bias yang berbeda. Semakin kecil panjang gelombangnya semakin besar indeks biasnya. Dispersi pada prisma terjadi karena adanya perbedaan indeks bias kaca setiap warna cahaya. Menggunakan lembaran prima membuat angka dari "primslets" berdampingan.Dibandingkan dari prisma satu yang besar, membolehkan ukuran dari kumpulan mesin untuk dikurangi beberapa tingkat. Sesungguhnya sekalipun sisa lintasan optik sama, lembaran prisma hampir datar. Bagaimanapun, kualitas 
dari perolehan gambar secara umum rendah dibandingkan teknik tradisional FTIR menggunakan kaca prisma.

\section{Sistem Absensi}

Sistem absensi yang merupakan sebuah sistem yang digunakan untuk mencatat daftar kehadiran setiap anggota instansi tersebut.Sistem absensi mencatat identitas anggota instansi dan waktu keluar-masuk anggotanya.sistem absensi juga mempunyai kemampuan untuk memberikan laporan yang akurat. Oleh karena itu, kebanyakan perusahaan memanfaatkan daftar kehadiran karyawan untuk menentukan kehadiran dan juga dapat memberikan informasi seberapa produktif perusahaan itu dengan karyawan yang di milikinya. Teknologi fingerprint adalah alat untuk memudahkan para karyawan dalam melakukan absensi dan juga menghindari adanya manipulasi data absensi yang sangat mudah dilakukan apabila absensi masih dilakukan secara manual.

\section{Bahasa Pemograman yang digunakan}

Visual Basic merupakan salah satu bahasa pemrograman yang mudah dipelajari dan handal, Visual Basic adalah bahasa pemrograman evev-driven yang berasal dari BASIC. Evendriven artinya program menunggu sampai adanya respon dari pemakai.Bahasa Visual Basic cukup sederhana dan menggunakan bahasa inggris yang umum digunakan, rencananya tidak perlu lagi menghafalkan sintak-sintak maupun format-format bahasa bermacam-macam. Di dalam Visual Basic sudah disediakan semuanya dalam pilihan pilihan yang tinggal diambil sesuai kebutuhan. Selain itu sarana pembangunan yang bersifat Visual memudahkan untuk mengembangkan program aplikasi Windows, bersifat mouse driver (digerakkan dengan mouse), dan berdaya guna tinggi.Visual Basic (VB) selain disebut sebagai bahasa pemrograman, juga sering disebut sebagai sarana (tool) untuk menghasilkan programprogram aplikasi berbasis Windows.

\section{Profil Perusahaan PT. Jasapower Indonesia}

PT Jasapower Indonesia (JPI) merupakan operator sistem Out-of-Pit Crusher and Conveyor system (OPCC) di tambang Tutupan AI. Sebagai bagian langkah peningkatan efisiensi yang berkelanjutan di sepanjang rantai pasokan, AE mulai mengotomasi aktivitas pengupasan lapisan penutup di Tutupan dengan memasang dan mengoperasikan OPCC pada tahun 2013. Dengan kondisi dimana tambang Tutupan telah berkembang menjadi salah satu tambang batubara terbesar di dunia, penanganan volume lapisan penutup yang dikupas dan diangkut dari tambang dalam jumlah yang sangat besar telah menjadi tantangan utama pengelolaan tambang karena lubang tambang semakin dalam dan jarak angkut semakin jauh, sehingga biaya angkut semakin tinggi.

OPCC dirancang untuk memenuhi parameter operasi AI dan dibangun dengan dua stasiun peremukan yang mengoperasikan sistem konveyor berkapasitas 7.000 ton per jam dan 12.000 ton per jam. Material lapisan penutup diangkut sejauh $10 \mathrm{~km}$ dari hopper menuju area pembuangan dan disebarkan menggunakan perangkat konveyor bergerak untuk membentuk 174| Mustafa, Juhriyansyah - Pengaruh Fingerprint Terhadap Jam Kerja Lembur di ..... 
area pembuangan yang sesuai dengan desain. Listrik untuk mengoperasikan OPCC dipasok anak perusahaan AE yaitu PT Makmur Sejahtera Wisesa, dari PLTU mulut tambangnya yang berkapasitas 2x30MW. Penggunaan pembangkit listrik bertenaga batubara ini mengurangi ketergantungan terhadap bahan bakar solar. OPCC menangani 7,9 Mbcm lapisan penutup pada tahun 2017, atau naik 55\% dari 5,1 Mbcm pada tahun 2016.

Di sepanjang tahun 2017, JPI terus mempertahankan keunggulan operasional, yang menekankan implementasi standar keselamatan operasional yang ketat. Sebagai hasilnya, JPI tidak mencatat adanya lost time injury dan prestasi ini mendapat pengakuan dari Gubernur Kalimantan Selatan dan Kementerian Tenaga Kerja melalui penghargaan keselamatan "free lost time safety award" pada tahun 2017. JPI juga mendapatkan peringkat emas dalam keselamatan pertambangan dan implementasi sistem manajemen dari AI.

\section{Jam Kerja Karyawan}

Karyawan di Perusahaan PT. Jasapower Indonesia dibagi menjadi 2 macam jam kerja yaitu :

\section{Karyawan Office (Staff)}

Jam kerja untuk karyawan staf yaitu : Pkl. 07.00 - 17.00

Roster Kerjanya : 5 hari kerja (senin - Jum'at), 2 hari libur (sabtu - minggu), sebagian karyawan untuk roster kerja ini, untuk karyawannya bisa dikondisikan untuk hari masuk kerjanya, maksudnya agar tidak tidak terjadi kekosongan karyawan saat ada kepentingan yang diperlukan (khusus untuk pekerjaan di bidang Planner \& Enggineering).

\section{Karyawan Site / lapangan \& Office (Non Staff)}

Jam kerja untuk karyawan Site yaitu : Pkl. 07.00 - 19.00 (day shift) \& Pkl. 19.00 07.00 (night shift).

Jam kerja untuk karyawan office (non staff) Pkl. 07.00 - 17.00 (hanya day shift).

Roster kerja karyawan site / lapangan : 4 Hari kerja, 2 hari libur. Terbagi menjadi 3 Team, yaitu Team A, B \& C. Yangmana jadwal kerjanya ssudah diatur agar tidak ada kekosongan di lapangan.

Roster kerja karyawan office (non staff) : 5 hari kerja (senin - jumat), 2 hari libur (sabtu, minggu).

Setiap Karyawan diwajibkan untuk absensi setiap awal dan akhir shift kerja. Karena, setiap data untuk masuk dan pulang kerja karyawan akan dimasukkankedalam arsip karyawan dan nantinya akan kumpulkan setiap bulannya dan pertanggal 10 yaitu tanggal untuk tutup buku absensi karyawan, yang nantinya diperlukan untuk perhitungan jam lembur karyawan non staff di perusahaan PT. Jasapower Indonesia.

\section{METODE PENELITIAN}

\section{Peralatan}

175| Mustafa, Juhriyansyah - Pengaruh Fingerprint Terhadap Jam Kerja Lembur di ..... 
Adapun peralatan yang digunakan yaitu sensor sidik jari, computer, driver sensor , bersamaan dengan software vb 6.0 yang digunakan untuk membuat program presensi sidik jari.

\section{Diagram Blok Penelitian}

Sistem yang dirancang merupakan hubungan antara sensor dengan PC dimana dihubungkan dengan komunikasi serial oleh USB. Adapun diagram blog sistem yang dirancang seperti gambar berikut:

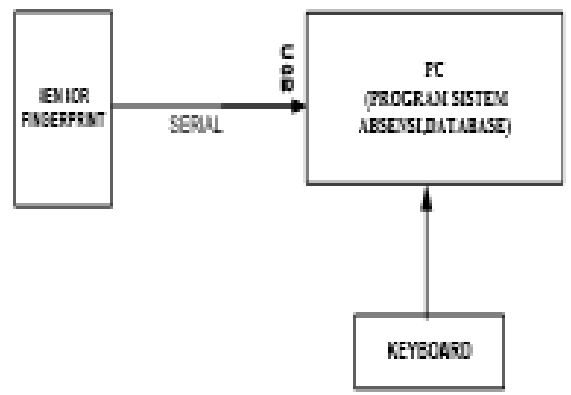

Gambar 2. Skema Proses Diagram Blog

(Sumber : Sinaga, Triandes \& Tamba, Takdir, 2013)

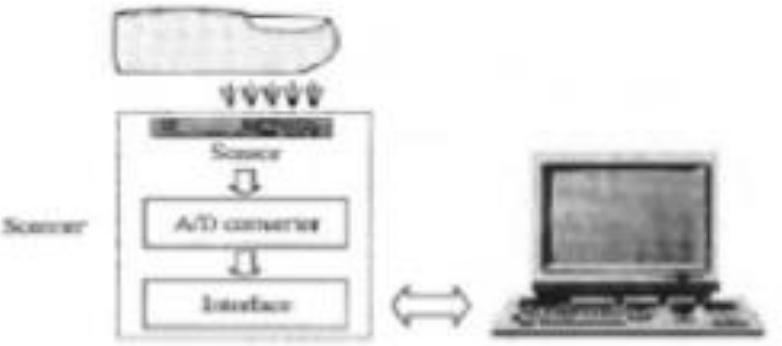

Gambar 3. Diagram dari Scanner Sidik Jari

(Sumber : Sinaga, Triandes \& Tamba, Takdir, 2013)

Sensor fingerprint yang digunakan merupakan sebagai alat pemindai sidik jari, dimana Sensor fingerprint memiliki tingkat sensitif yang tinggi. Sensor akan melakukan proses scan pemindaian untuk setiap jari tangan yang mengenai sensor tersebut dan data hasil scan dari sensor akan dikirimkan ke komputer melalui USB .Proses scan yang berlangsung melalui proses fisika yang cukup panjang. Setelah dilakukan registrasi untuk suatu jari maka data tersebut disimpan dalam database (basis data). Maka semua data tersebut di proses pada komputer. Dimana proses pendaftaran sidik jari dengan menempel 4 kali sidik jari ke permukaan sensor yang hendak di daftar. Proses pendaftaran sidik jari dilakukan dengan mengambil sampel jari sebanyak 4 kali, namun disaat proses verfikasi, si pengguna cukup 
sekali meletakkan jari yang telah di daftar tadi dengan meletakkan jari yang telah terdaftar ke permukaan sensor, maka sensor akan mengirimkan data hasil baca sensor ke komputer, maka data tersebut akan dibandingkan dengan database yang sudah ada, apabila ternyata data yang dibaca sensor memiliki kesamaan ciri dengan data yang ada dalam basis data maka proses verifikasi berlangsung sukses dan apabila data uji hasil baca sensor tidak menemukan adanya kesamaan ciri dengan data yang ada pada database proses akan ditolak dengan kata lain proses verifikasi gagal. Hasil yang diperoleh akan ditampilkan pada komputer. Pengiriman data hasil baca sensor fingerprint di kirim ke komputer melalui USB. Dimana sebelumnya, data analog yang diperoleh akan di konversikan ke data digital pada sensor.

Sidik jari terdiri dari kontur tinggi dan rendah. Bagian ini akan memantulkan cahaya dengan intensitas cahaya yang berbeda. Tentunya, bagian cekungan akan memantulkan intensitas cahaya lemah, sebaliknya bagian yang timbul akan memantulkan intensitas cahaya yang lebih terang. Hal ini lah yang selanjutnya diproses sehingga dapat membedakan suatu jari dengan jari yang lain.

\section{Perancangan Perangkat Lunak Sistem Presensi}

\section{- Perancangan Menu Utama}

Menu utama merupakan langkah awal untuk melakukan pemilihan kerja yang akan di dilakukan. Pada menu utama akan ditampilkan tahap awal registrasi user, verifikasi sidik jari, dan laporan Presensi.

\section{- Perancangan Menu Proses Registrasi}

Perancangan program untuk jendela registrasi bertujuan untuk memudahkan proses input data pengguna (user ) sistem presensi yang nantinya akan disimpan ke dalam basis data. Pada jendela registrasi dirancang tampilan ID, Nama, serta jari tangan yang hendak di daftar. Untuk penelitian ini ID berupa angka dengan maksimum 8 digit.Tujuan ditentukannya ID dan Nama untuk memudahkan pada saat looping program agar berlangsung singkat dan langsung menuju sasaran. Setelah nomor ID diterima, dilanjutkan pengisisan nama. Saat nama belum diisi tetapi melakukan proses registrasi maka akan muncul pesan "Nama tidak boleh kosong”. Jika nomor ID dan Nama telah di isi maka proses selanjutnya memilih jari tangan yang hendak didaftar, setelah itu klik registrasi untuk melakukan pemindaian. Bila proses pengambilan sidik jari telah sukses sebanyak empat kali maka proses registrasi berhasil yang berarti data user akan disimpan ke dalam basis data. 


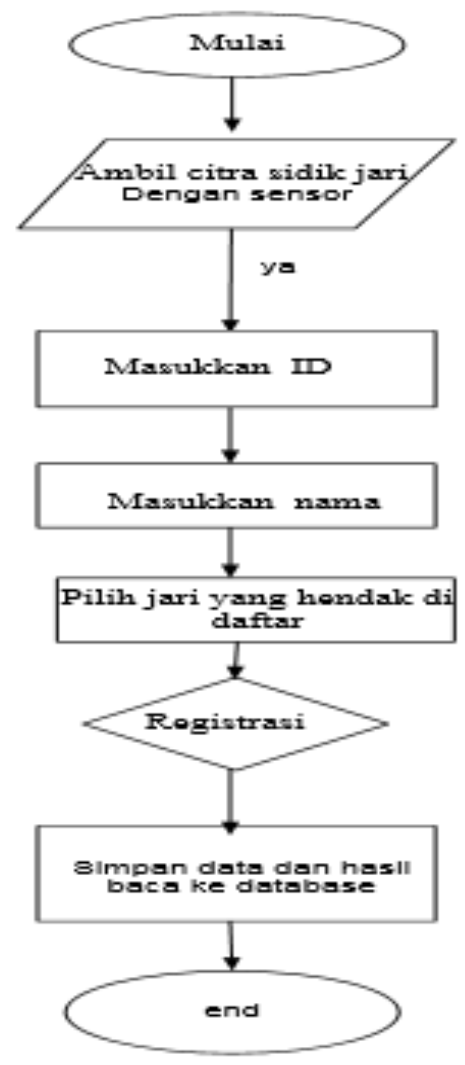

\section{Gambar 4. Flowchart Proses}

(Sumber : Sinaga, Triandes \& Tamba, Takdir, 2013)

- Perancangan Menu Proses Verifikasi

Proses verifikasi dilakukan dengan menempelkan jari pada permukaan sensor kemudian sensor melakukan proses verifikasi citra sidik jari yang diterima dan membandingkan dengan citra sidik jari pada basis data Kemungkinan yang terjadi saat sidik jari telah berhasil diambil maka hasil verikasinya sukses atau gagal. Kemungkinan yang lain adalah saat lima kali sidik jari yang diakuisisi oleh sensor ternyata hasilnya tidak cocok (citra tidak memenuhi syarat) maka tampilan programnya adalah not found. Namun apabila sidik jari yang diterima sensor cocok dengan data yang disimpan pada basis data maka program akan menampilkan ID nama berserta foto dan gambar sidik jari pengguna. 


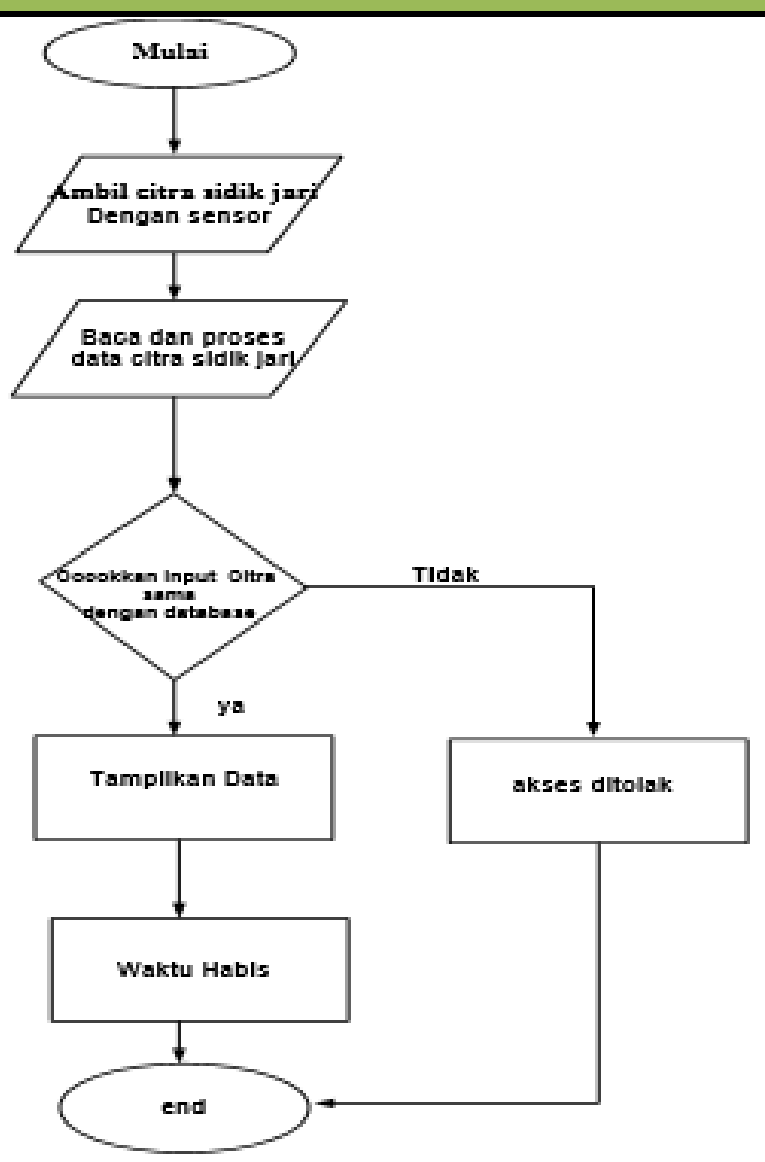

Gambar 5. Flowchart Proses Verifikasi

(Sumber : Sinaga, Triandes \& Tamba, Takdir, 2013)

Pada flowchart diatas boleh di jelaskan untuk yang pertama sekali setelah sensor dan komputer telah di aktifkan maka akan di lakukan proses registrasi pengguna. Dengan memasukkan nilai ID sebanyak 8 digit kemudian memasukkan nama pengguna, kemudian memilih jari yang hendak di daftarkan yang hendak disimpan dalam basis data. Setelah itu user mengambil citra sidik jari tangan sebanyak empat kali dengan meletakkan jari pada permukaan sensor. Setelah proses registrasi telah selesai data yang sudah diregistrasi akan disimpan ke dalam basis data.

\section{HASIL DAN PEMBAHASAN}

\section{Proses Kegiatan Absensi di PT. Jasapower Indonesia}

Setiap awal shift atau saat karyawan sampai ke lokasi kerja, diharuskan untuk langsung melakukan absensi di tempat yang disediakan oleh perusahaan. Adapun tempat absensi yang tersedia yaitu :

1. Absensi di ruang tunggu depan Office

179| Mustafa, Juhriyansyah - Pengaruh Fingerprint Terhadap Jam Kerja Lembur di ..... 
Untuk karyawan area warehouse, driver dan karyawan yang akan hand over pekerjaan dari shift siang ke malam atau sebaliknya.

2. Absensi didalam Office JPI Km. 80

Untuk karyawan yang area kerjanya hanya didalam office JPI Km. 80

3. Absensi di Workshop CV220

Untuk karyawan yang area kerjanya didalam Workshop CV220 atau team maintenance lapangan

4. Absesnsi di Office CV260

Untuk karyawan team operation.

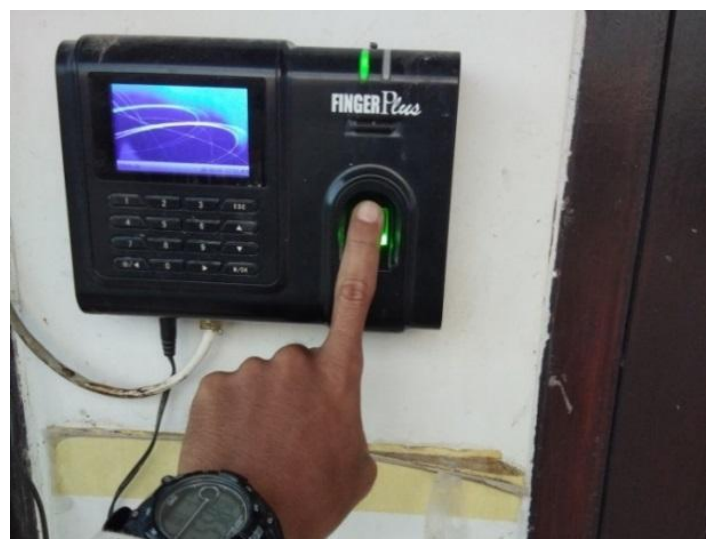

Gambar 6. Proses Absensi

(Sumber : Absensi di PT JPI)

Setiap karawan harus memastikan setiap absensinya diterima oleh mesin finger print atau dari mesin terdengar suara " Terima Kasih ". Jika tetap gagal tentunya absensi karyawan tersebut tidak akan terinput ke database karyawan dan harus diinfokan ke bagian Human Resource (HR) sebelum tutup buku setiap tanggal 10.

Karyawan yang hadir dan juga absen akan terlihat dimonitor kehadiran di dalam Office JPI Km. 80 setiap harinya yang sudah disesuaikan dengan jadwal kehadiran karyawan pada hari tersebut.

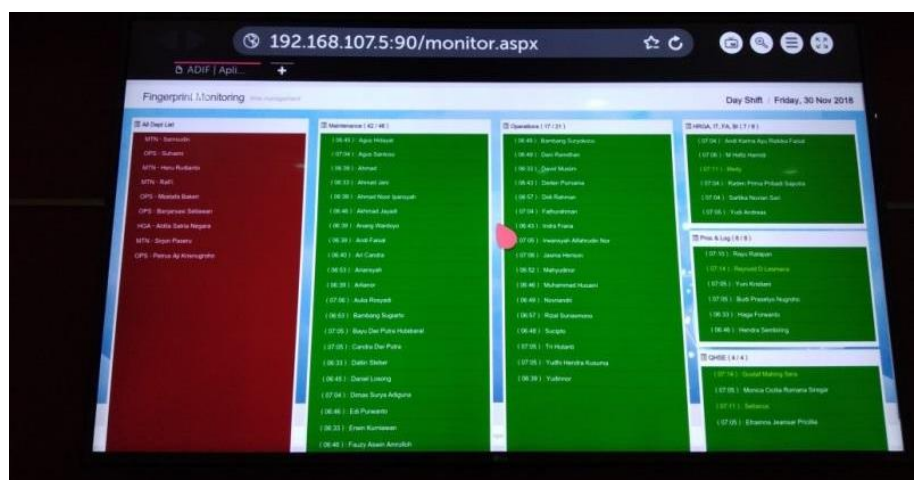

180| Mustafa, Juhriyansyah - Pengaruh Fingerprint Terhadap Jam Kerja Lembur di ..... 


\section{Gambar 7. Absensi Kehadiran Karyawan}

(Sumber : Absensi di PT JPI)

Dari gambar terlihat, warna hijau untuk karyawan yang hadir dan warna merah untuk karyawan yang tidak hadir (absen) atau kegagalan dalam proses absensi.

\section{Perhitungan Jam Kerja Lembur Karyawan}

Perhitungan jam kerja lembur karyawan hanya ditujukan untuk karyawan non staff, karena untuk karyawan staff, menggunakan pembayaran all in (sudah dibayar beserta gaji pokok setiap bulannya), sehungga tidak ada perhitungan jam kerja lemburnya.

- Rumus Perhitungan Jam lembur di Perusahaan PT. Jasapower Indonesia yaitu :

1. Pada hari kerja biasa (sesuai jadwal roster)

Jam Pertama $=$ X (dikali) 1,5 Jam lembur

Jam ke $2-$ selebihnya $=$ X (dikali) 2 Jam lembur

2. Pada saat libur (bekerja saat jadwal kerja libur)

Pertama - ke $7=X$ (dikali) 2 Jam lembur

Jam ke $8=X$ (dikali) 3 Jam lembur

Jam ke 9 - selebihnya = X (dikali) 4 Jam lembur

Sehingga perhitungan jam kerja lembur karyawan terbagi 2 yaitu :

\section{Karyawan Office (Non Staff)}

Jam Kerjanya : Pkl. 07.00 - 17.00, jam kerja efektifnya yaitu 8 jam. Jadi 10 jam kerja dari Pkl. 07.00 - 17.00, dikurangi 1 jam istirahat, sehingga kelebihan jamnya yaitu 1 jam. Jika dimasukkan ke rumus menjadi, 1 x 1.5 jam = 1,5 jam kerja lembur.

2. Karyawan Site / Lapangan (Non Staf)

Jam Kerjanya : Pkl. 07.00 - 19.00, jam kerja efektifnya yaitu 7 jam. Jadi 12 jam kerja dari Pkl. 07.00 - 19.00, dikurangi 1 jam istirahat, sehingga kelebihan jamnya yaitu 4 jam. Jika dimasukkan ke rumus menjadi :

Jam Pertama x 1.5 jam =1,5 jam kerja lembur. Jam ke $2-$ ke 4 , menjadi $3 \times 2$ jam $=6$ jam kerja lembur. Totalnya menjadi 7,5 Jam kerja lembur.

\section{Perhitungan Jam Kerja Lembur Setelah Absensi FingerPrint dari Sunfish}

Sunfish yaitu web internet internal perusahaan yang dapat dibuka untuk informasi pribadi dari karyawan itu sendiri yang sifatnya privasi. Setiap karyawan akan diberikan user login dan password yang berbeda saat akan memasuki web sunfish ini. Isi sunfish ini berupa informasi dari data pribadi karyawan sampai absensi karyawan dan karyawan bias melihat langsung berapa jam kerja yang bisa didapatnya dan benefit yang didapatnya setiap bulannya. Berikut ini merupakan contoh gambar hasil absensi dan perhitungan jam kerja karyawan staf dan non staf dari web sunfish :

1. Absensi kehadiran kerja karyawan staff

181| Mustafa, Juhriyansyah - Pengaruh Fingerprint Terhadap Jam Kerja Lembur di ..... 

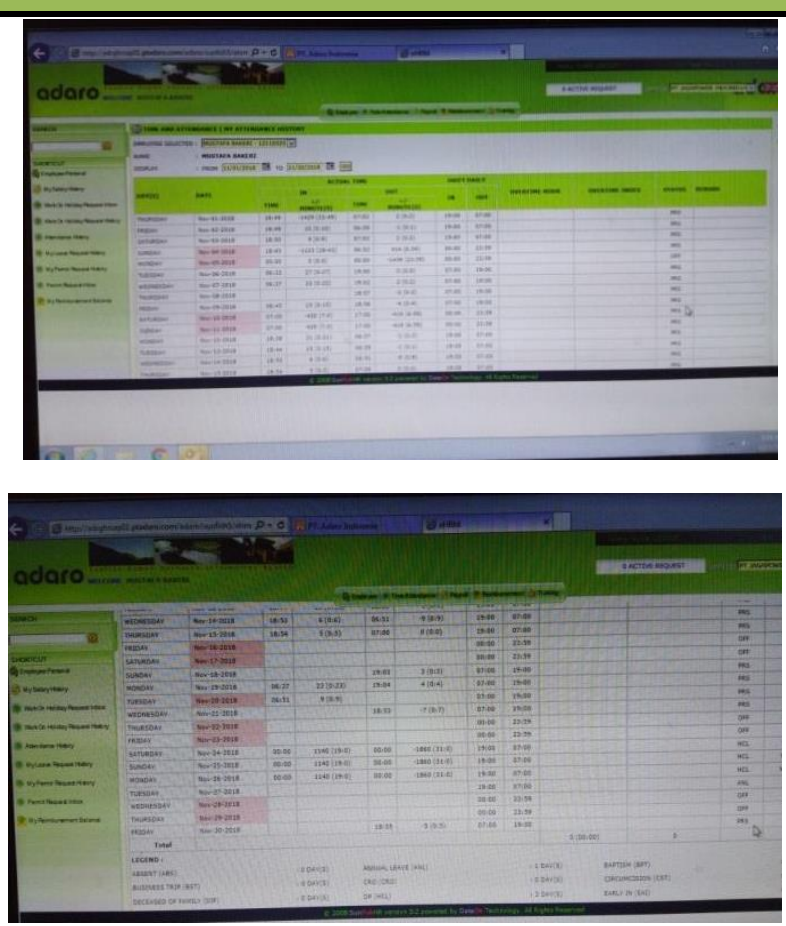

\section{Gambar 8. Absensi Karayawan Staff}

(Sumber : Server internal di PT JPI)

Dari gambar terlihat absensi kehadiran karyawan setiap bulannya. Untuk karyawan staff juga tidak ada terinput data jam kerja lembur (overtime).

2. Absensi Absensi kehadiran dan perhitungan jam kerja karyawan Non Staff
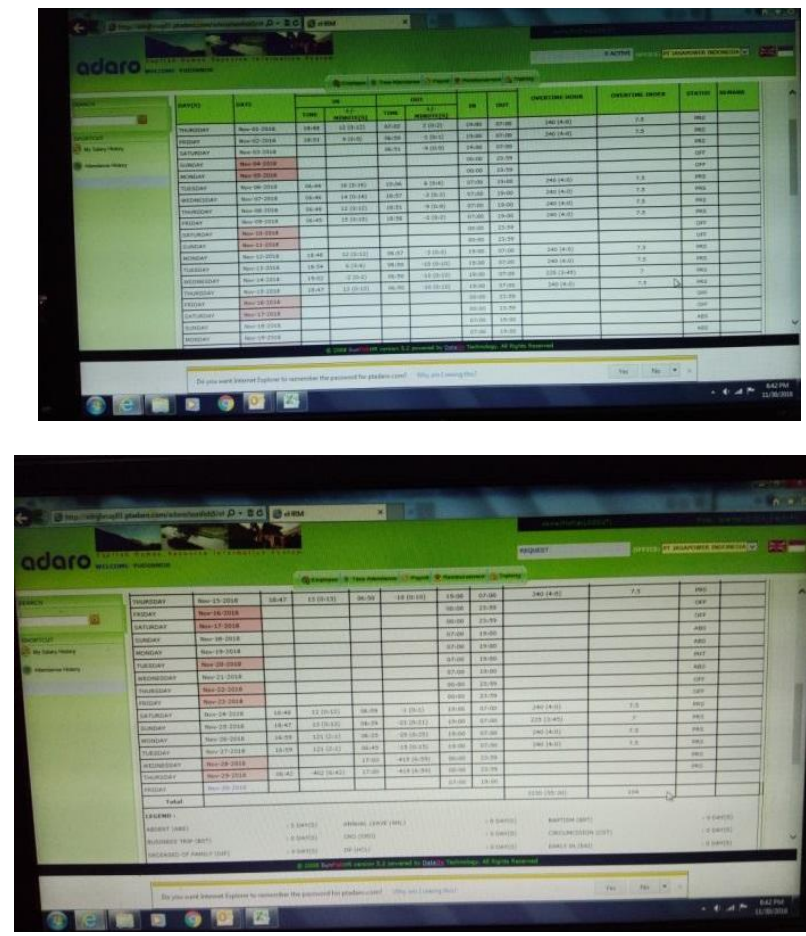

182| Mustafa, Juhriyansyah - Pengaruh Fingerprint Terhadap Jam Kerja Lembur di ..... 


\section{Gambar 9. Absensi Karyawan Non Staff}

(Sumber : Server internal di PT JPI)

Dari gambar terlihat absensi kehadiran karyawan setiap bulannya, serta jumlah jam kerja lembur (overtime) karyawan.

\section{KESIMPULAN}

Kesimpulan dari penelitian diatas adalah:

1. Sistem absensi kehadiran di perusahaan PT. Jasapower Indonesia menggunakan sistem finger print sangat efektif dan akan mendorong disiplin kerja yang bagus untuk setiap karyawannya.

2. Absensi kehadiran menggunakan finger print sangat berperan dalam perhitungan jam kerja lembur karyawan dan akan memotivasi karyawan untuk menjaga kondisi badan agar selalu fit dan bisa berhadir untuk bekerja. Karena kehadiran akan mempengaruhi benefit yang diperoleh karyawan khususnya karyawan non staff.

3. Karyawan harus selalu memastikan kehadirannya dan dapat mengecek kehadiran di monitor kehadiran di dalam Office JPI Km. 80 atau bisa membuka absensi kehadirannya di web sunfish yang disediakan oleh perusahaan, sehingga dapat menginfokan ke tim Human Resource (HR) jika ada kehadiran yang belum terinput sebelum tutup buku setiap tanggal 10.

\section{SARAN}

Selain itu berdasarkan hasil penelitian dan kesimpulan yang dapat ditarik dari penelitian ini, saran yang bisa diberikan adalah:

1. Tim Human Resource (HR) harus mensosialisasikan akan pentingnya absensi kehadiran sistem finger print dan karyawan harus memahami fungsi dan peranannya.

2. Setiap leader karyawan harus membuat absensi kehadiran manual tersendiri untuk kehadiran bawahannya atau karyawan non staff, yang bertujuan sebagai bahan pegangan (backup) jika absensi bawahannya tidak terinput atau kosong.

\section{DAFTAR PUSTAKA}

[1]. Serikat Pekerja, 2018. Perjanjian Kerja Bersama, PT. Jasapower Indonesia, Banjarmasin.

[2]. Sinaga, Triandes \& Tamba, Takdir, 2013. Sistem Presensi dengan Metode SidikJari Menggunakan Sensor Fingerprint dengan Tampilan Pada PC. Journal. Fakultas Fisika Instrumentasi. Univ. Sumatera Utara. Medan 
[3].https://media.neliti.com/media/publications/221183-none.pdf

[4].http://www.adaro.com/pages/read/7/23/Logistic\%20and\%20Services

[5].https://core.ac.uk/download/pdf/35379452.pdf

[6].https://repository.usd.ac.id/7125/2/115314033_full.pdf

[7].http://eprints.ums.ac.id/49040/4/Naskah\%20Publikasi_eko.pdf

[8].https://www.researchgate.net/publication/328351995_Sistem_Informasi_Kehadiran_Dose n_dan_Mahasiswa_Menggunakan_Sidik_Jari_pada_Program_Studi_Informatika_Universitas _Tanjungpura

[9].http://repository.unej.ac.id/bitstream/handle/123456789/79146/3.\%20Dewi\%20Larasatri.p df?sequence $=1$

[10].http://repository.amikom.ac.id/files/publikasi_08.21.0379.pdf 